\title{
Selection and ranking method for currently used pesticides (CUPs) monitoring in ambient air
}

\author{
Arnaud Giusti $^{1}$ (1) • Catherine Pirard ${ }^{2}$ - Corinne Charlier $^{2}$ - Jérôme C. J. Petit ${ }^{1}$. \\ Sophie Crevecoeur ${ }^{1}$ - Suzanne Remy ${ }^{1}$
}

Received: 21 June 2017 / Accepted: 14 September 2017

(C) Springer Science+Business Media B.V. 2018

\begin{abstract}
Chronic exposure to pesticides can induce adverse human health effects. Even though ingestion is considered as the main exposure pathway, it is now suggested that inhalation might also be important not only in rural but also in urban locations. Therefore, assessment of currently used pesticides (CUPs) concentrations in ambient air is important for better understanding of human exposure through inhalation and potential health effects. Analytical methods do not allow assessing ambient air concentration of all the CUPs registered. Designing a cost-effective and a fitted-for-purpose monitoring strategy at the local/regional scale must therefore rely on a methodology allowing targeting CUPs by a ranking approach accounting for the most relevant selection criteria. In this study, after a first selection, a ranking method is used to identify most relevant CUPs for ambient air assessment in Wallonia, Belgium. This method took into account not only toxicological endpoints but also national and regional data on sales and uses along with other uses criteria. Moreover, probability to detect CUPs in ambient air was investigated using international, national, and regional studies and physicochem-
\end{abstract}

Electronic supplementary material The online version of this article (https://doi.org/10.1007/s11869-017-0516-6) contains supplementary material, which is available to authorized users.

Arnaud Giusti

a.giusti@issep.be

1 Direction of Chronic Risks, Environment and Health Team, Institut Scientifique de Service Public (ISSeP), 4000 Liège, Belgium

2 Laboratory of Clinical, Forensic and Environmental Toxicology, University of Liege (ULg), CHU (B35), 4000 Liege, Belgium ical properties. The ranking method used three main criteria (i.e., chronic toxicity, sales and uses, and presence in ambient air), which are divided in 17 sub-criteria, to provide the most accurate identification of CUPs that might be measured in ambient air and that might impact human health. After final selection based on analytical methods, 43 CUPs were further submitted to analytical method development.

Keywords Currently used pesticides $\cdot$ Ambient air monitoring $\cdot$ Prioritization $\cdot$ Ranking $\cdot$ Toxicity . EXPOPESTEN

\author{
Abbreviations \\ AASQA French Accredited Associations for Air Quality \\ Monitoring \\ ADI Acceptable daily intake \\ AMPA Aminomethylphosphonic acid \\ CRAAQ Quebec Reference Center for Agriculture and \\ Agri-Food \\ CUPs Currently used pesticides \\ ETU Ethylene thiourea \\ IARC International Agency for Research on Cancer \\ PPDB Pesticides Properties Database \\ US-EPA US Environmental Protection Agency \\ WHO World Health Organization
}

\section{Introduction}

Due to their massive use for intensive food production and preservation in both developed and developing countries, pesticides are among the most widely used anthropogenic 
chemicals thus contributing to a global contamination of the environment (Baraud et al. 2003; Yusà et al. 2009; Espallardo et al. 2012). Chronic exposure to pesticides can induce adverse human health effects such as cancer, endocrine disruption, and developmental and reproductive toxicity (Kamel and Hoppin 2004; Mnif et al. 2011; Mostafalou and Abdollahi 2013; NTP 2014). Humans are exposed to pesticides through three main pathways, namely dermal exposure, ingestion, and inhalation. Even though ingestion is considered as the main pathway for chronic exposure to pesticides (Sheldon 2010), there are growing evidences for a significant contribution of inhalation exposure in rural as well as in urban locations (Baraud et al. 2003; Scheyer et al. 2007; Schummer et al. 2010). Indeed, pesticides are emitted in ambient air through spray drift and volatilization from plants and soil with an estimated loss of up to $90 \%$ of the applied dose either during or after application (Bedos et al. 2002; Espallardo et al. 2012; Sarigiannis et al. 2013). Even though currently used pesticides (CUPs) metabolize and degrade more efficiently than historical ones (e.g., organochlorine compounds), several studies in North America and Europe reported ambient air concentrations in rural and urban areas as well as in remote sites located far from any pesticide uses (LeNoir et al. 1999; Baraud et al. 2003; Yao et al. 2006; Scheyer et al. 2007; Aulagnier et al. 2008; Gouin et al. 2008; Coscollà et al. 2010; Kurt-Karakus et al. 2011; Mai et al. 2013). While CUPs levels in ambient air are usually in the $\mathrm{ng} / \mathrm{m}^{3}$ range, some are measured at concentrations over $100 \mathrm{ng} / \mathrm{m}^{3}$ in agricultural regions (Baraud et al. 2003; Garron et al. 2012; Hart et al. 2012; Coscollà et al. 2013) hence potentially affecting health of exposed populations.

Therefore, the measurement of CUPs concentrations in ambient air is required for a better understanding of non-dietary human exposure and to assess potential health effects related to inhalation. The major drawback to cope with ambient air pesticides assessment is the diversity of active substances used. Indeed, more than 400 active substances were registered in European Union in 2014 (EU 2014), but analytical methods do not allow assessing all the registered molecules in ambient air (Segawa et al. 2014). Moreover, all CUPs are not susceptible to be found in ambient air either due to low volatilization or to fast metabolization. The selection of most relevant CUPs for ambient air concentration monitoring appears then a crucial point before sampling and analysis.

Designing a cost-effective and a fitted-for-purpose monitoring strategy at the local/regional scale must therefore rely on a methodology allowing targeting CUPs by a ranking approach accounting for the most relevant selection criteria. Environmental loads are related to the amount used, to the frequency of application, and to the physicochemical properties of the CUPs (Gunier et al. 2001; Juraske et al. 2007; Egeghy et al. 2011). Thus, identifying and prioritizing pesticides of concern need to emphasize (i) pesticide uses, (ii) toxicity related to chronic exposure, and (iii) exposure potential in order to more accurately assess health risks related to pesticides (Sugeng et al. 2013). Different screening and ranking methods were developed in Europe, the USA, and Canada to identify and quantify the degree of concern for pesticide toxicity to human health and ecosystems related to exposure (Reus et al. 2002; Juraske et al. 2007; Egeghy et al. 2011; Mitchell et al. 2013; Segawa et al. 2014). These modeling approaches were developed in response to the need for rapid and efficient risk characterization with respect to the thousands of chemicals used throughout industry and agriculture. The prioritized lists of chemicals established using models helped identifying chemicals of highest concern regarding toxicity and uses so to ensure better protection for human and ecosystem health (Egeghy et al. 2011; Mitchell et al. 2013). Moreover, these modeling approaches are usually developed on a nationwide scale (Egeghy et al. 2011; Mitchell et al. 2013) but can sometimes be applied to smaller scales thus responding to local needs for management or health outcomes related to local exposures (Gunier et al. 2001; Sugeng et al. 2013; Segawa et al. 2014).

These lists are developed and used in a regulatory purpose (Egeghy et al. 2011; Mitchell et al. 2013), but environmental concentrations and biomarker levels of identified chemicals, which are required to assess ecosystem and human exposure, are not further measured. Recently, a study focused on the use of a prioritization method to select pesticides to be analyzed in ambient air for a yearlong air monitoring study in California (Segawa et al. 2014). This study used four criteria (i.e., statewide reported uses, volatility, priority in risk assessment, and availability of analytical methods) to assign points to the top 100 pesticides used in agriculture in California allowing selecting 13 pesticides monitored in ambient air. In addition, some lower scoring pesticides were monitored because they were easy to include in the multi-residue analysis used to achieve a total of 24 CUPs (Segawa et al. 2014).

Belgium is among the five largest pesticide consumers in Europe when considering the amount used per agricultural acreage (PWRP 2013) with more than 300 plant protection products registered for professional and non-professional uses in 2014. The EXPOPESTEN study aims at assessing exposure of Walloon population to CUPs through ambient air measurement and biomonitoring. For this study, we developed a selection and a ranking method to identify CUPs that will be monitored in ambient air in Wallonia, Belgium, during a yearlong study. In this study, CUPs are selected using three main criteria (i.e., chronic toxicity, sales in Belgium and uses in Wallonia, probability of presence in ambient air). These three main criteria are divided in a total of 17 sub-criteria. Points are attributed to each sub-criterion to establish a prioritized list to select relevant CUPs that will be analyzed in ambient air in Wallonia over a yearlong. This selection method considered all registered CUPs to finally select the most relevant for final ambient air analysis. 


\section{Materials and methods}

In Belgium, over 300 plant protection products were registered for both professional and non-professional uses in 2014. Prior to the ranking of CUPs for ambient air analysis, the list of CUPs is reduced by selecting the most relevant candidates based on their sales and uses and on their chronic toxicity. Points are then attributed to CUPs for each of the 17 sub-criteria using information from selected databases. The total of the points attributed to each CUP allowed ranking candidates. CUPs are finally selected based on the possibility to develop analytical method for ambient air monitoring.

\section{Currently used pesticides selection}

Some microorganisms (e.g., Bacillus subtilis, Streptomyces...), molecules derived from plants and animals (e.g., fatty acids, rapeseed oils...), and insect pheromones (e.g., codlemon, $n$-tetradecyl acetate...) are listed among the registered plant protection products for their uses as fungicides or insecticides. Microorganisms and molecules derived from animals and plants naturally occur in the environment and are thus out of the scope of this study and discarded from the candidate list.

\section{Selection based on sales and uses}

To further reduce the list of candidates for the ranking method, some CUPs are removed based on their uses. Indeed, CUPs defined as "other plant protection products" in the Annex III of the Commission Regulation (EU) No. 656/2011 of 7 July 2011 Implementing Regulation (EC) No. 1185/2009 of the European Parliament and of the Council concerning statistics on pesticides (OJEU 2011) are used as adjuvants and surfactants in combination with other CUPs defined as active substances. These other plant protection products are out of the scope of our study and were also removed from the list submitted to the selection method.

After reduction, the number of CUPs retained (i.e., 231) is still difficult to manage for the ranking. Therefore, Belgian sales for the year 2010 to 2013 are used to further reduce the number of CUPs considered for the ranking using 17 subcriteria. These data are compiled in the frame of Eurostat requirements for pesticides sales statistics in Europe and were obtained from the Belgian Federal Public Service. The CUPs representing $95 \%$ of the total quantities sold between 2010 and 2013 to both professional and non-professional users in Belgium are retained in the candidate list.

\section{Selection based on chronic toxicity}

As the objective of pesticide management is to ensure protection of the environment as well as human health (OJEU 2009;
Egeghy et al. 2011), chronic toxicological data are considered for the 231 CUPs. Analysis of toxicological data will help identify CUPs sold in lower quantities, which were not selected in the list of CUPs representing the 95\% highest quantities sold in Belgium, but with potentially high human toxicity. Chronic toxicity criteria used are carcinogenicity, neurotoxicity, endocrine disruption, developmental and reproductive toxicity, and mutagenicity and genotoxicity (Table 1). As lack of data in databases is a critical endpoint when assessing pesticide toxicity (Sugeng et al. 2013), at least two databases are consulted for each toxicological endpoint. The first, Pesticides Properties DataBase (PPDB) developed by the Agriculture \& Environment Research Unit of the University of Hertfordshire, is a comprehensive compilation of pesticide chemical identity, physicochemical properties, and data on human and environmental health (Lewis et al. 2016). The second, SAgE pesticides database developed by the Quebec Reference Center for Agriculture and Agri-Food (CRAAQ) in Canada, is also dedicated to pesticides and compiles physicochemical properties along with toxicological and ecotoxicological data (Samuel et al. 2012). These two databases, specific to pesticides and peer reviewed by working groups of specialists, are used for all toxicological criteria considered (Table 1). Moreover, two additional data sources not specific to pesticides are investigated to assess carcinogenicity. The first is the International Agency for Research on Cancer (IARC) list of carcinogens. The IARC is the specialized cancer agency of the World Health Organization (WHO) and regularly publishes monographs in which environmental factors that increase the risk of human cancer are identified and ranked based on the strengths of association between exposure and carcinogenicity (IARC 2006; Cogliano et al. 2011). The second source used is the list of chemicals evaluated for carcinogenic potential that is annually released by the Office of Pesticide Programs of the US Environmental Protection Agency (US-EPA 2014).

The CUPs with suspected or proven toxicity for at least three toxicological endpoints reported in at least one of the databases are retained for the ranking method.

\section{Currently used pesticides ranking}

CUPs retained from both sales and uses selection and chronic toxicity selection are then submitted to the ranking method. In this method, three main criteria are defined: chronic toxicity, sales and uses, and presence in ambient air. These criteria are divided in a total of 17 sub-criteria. Points are attributed for all the 17 sub-criteria to each candidate CUP based on data available. Points are then summed to rank CUPs for the final selection based on the possibility to develop analytical method for ambient air monitoring. The sub-criteria and points allocated are described in Table 1. 
Table 1 Points assigned to the different criteria used to prioritize chemicals for ambient air monitoring in Walloon Region, Belgium, in ranking method

\begin{tabular}{|c|c|c|c|c|c|}
\hline Criteria & Points & & & & \\
\hline \multicolumn{6}{|l|}{1 Chronic toxicity-maximum 14 points } \\
\hline 1.A — acceptable daily intake (mg/kg bw/day) & $\begin{array}{l}0 \text { - not } \\
\text { applicable }\end{array}$ & $1-\mathrm{ADI} \geq 0.1$ & $\begin{array}{l}2- \\
0.03>\mathrm{AD}- \\
\mathrm{I} \geq 0.1\end{array}$ & $\begin{array}{l}3- \\
\quad 0.01>A D- \\
I \geq 0.03\end{array}$ & $4-\mathrm{ADI}<0.01$ \\
\hline 1.B-carcinogenicity & 0 - not likely & $\begin{array}{l}2 \text { - suspected or } \\
\text { proved }\end{array}$ & & & \\
\hline 1.C-neurotoxicity & 0 - not likely & $\begin{array}{l}2-\text { suspected or } \\
\text { proved }\end{array}$ & & & \\
\hline 1.D-endocrine disruption & 0 - not likely & $\begin{array}{l}2-\text { suspected or } \\
\text { proved }\end{array}$ & & & \\
\hline 1.E-reproductive and developmental toxicity & 0 - not likely & $\begin{array}{l}2 \text { - suspected or } \\
\text { proved }\end{array}$ & & & \\
\hline 1.F — mutagenicity and genotoxicity & 0 - not likely & $\begin{array}{l}2 \text { - suspected or } \\
\text { proved }\end{array}$ & & & \\
\hline \multicolumn{6}{|l|}{2 Sales and uses - maximum 21 points } \\
\hline $\begin{array}{l}\text { 2.A-quantity sold in Belgium between } 2010 \\
\text { and } 2013\end{array}$ & 0 - not sold & $1-0$ to $10,385 \mathrm{~kg}$ & $\begin{array}{c}2-10,386 \text { to } \\
66,778 \mathrm{~kg}\end{array}$ & $\begin{array}{r}3-66,779 \text { to } \\
122,722 \mathrm{~kg}\end{array}$ & $\begin{array}{l}4 \text { - over } \\
122,723 \mathrm{~kg}\end{array}$ \\
\hline $\begin{array}{l}\text { 2.B-quantity used in Wallonia between } 2010 \\
\text { and } 2013\end{array}$ & 0 - not used & $1-0$ to $867 \mathrm{~kg}$ & $2-868$ to $8443 \mathrm{~kg}$ & $\begin{array}{l}3-8444 \text { to } \\
31,049 \mathrm{~kg}\end{array}$ & $\begin{array}{l}4 \text { over } \\
31,050 \mathrm{~kg}\end{array}$ \\
\hline $\begin{array}{l}\text { 2.C-areas treated in Wallonia between } 2010 \\
\text { and } 2013\end{array}$ & 0 - not used & $1-0$ to 4059 ha & $2-4060$ to & $\begin{array}{r}3-38,278 \text { to } \\
118,924 \text { ha }\end{array}$ & $\begin{array}{l}4 \text { - over } \\
118,925 \text { ha }\end{array}$ \\
\hline 2.D - number of commercial formulations & 0 - not sold & $1-1$ to 5 & $2-6$ to 10 & $3-10$ to 20 & 4 - over 20 \\
\hline 2.E - number of crops treated & 0 -not used & $1-1$ to 2 & $2-3$ to 4 & 3 - over 5 & \\
\hline 2.F-non-professional uses & $0-$ no & 1 -yes & & & \\
\hline 2.G_-biocide uses & $0-$ no & $1-$ yes & & & \\
\hline \multicolumn{6}{|l|}{3 Presence in ambient air-maximum 13 points } \\
\hline 3.A-volatility & $\begin{array}{l}1 \text { - low } \\
\text { volatility }\end{array}$ & $\begin{array}{l}2 \text {-medium } \\
\text { volatility }\end{array}$ & 3 -high volatility & & \\
\hline $\begin{array}{l}\text { 3.B-maximum concentrations measured in } \\
\text { ambient air }\end{array}$ & 0 - no data & $1<0.5 \mathrm{ng} / \mathrm{m}^{3}$ & $2-0.5$ to $1 \mathrm{ng} / \mathrm{m}^{3}$ & $3-1$ to $10 \mathrm{ng} / \mathrm{m}^{3}$ & $\begin{array}{l}4-\text { over } \\
10 \mathrm{ng} / \mathrm{m}^{3}\end{array}$ \\
\hline 3.C-number of studies & 0 - no data & $1-1$ to 5 & $2-6$ to 10 & 3 -over 10 & \\
\hline 3.D - last year of detection in a French study & 0 - no data & $1-2000$ to 2005 & $2-2006$ to 2010 & 3 -after 2010 & \\
\hline
\end{tabular}

\section{Criterion 1: chronic toxicity criterion}

The chronic toxicity criterion is divided into six sub-criteria (Table 1). Five of them were previously used for the reduction of the candidate list (i.e., carcinogenicity, neurotoxicity, endocrine disruption, developmental and reproductive toxicity, and mutagenicity and genotoxicity). Points are allocated to CUPs based on information available in each database consulted for chronic toxicity (i.e., PPDB, SAgE, IARC, US-EPA). Then, only the highest score is retained for the final ranking as it is a more conservative assumption (Sugeng et al. 2013). One more toxicity sub-criterion (i.e., acceptable daily intake (ADI)) is considered in the ranking method. ADI is defined by the European Food Safety Authority (EFSA) as an estimate of the amount of the CUP that can be consumed (i.e., ingestion exposure through food and beverages) over a lifetime without presenting an appreciable risk to human health. ADI is evaluated using results of long-term studies in animals and observations on human. Though, this sub-criterion is useful to evaluate the toxicity of CUPs related to the dose of exposure. ADI data calculated by the EFSA are compiled from the PPDB database.

\section{Criterion 2: sales and uses}

In addition to quantity sold in Belgium between 2010 and 2013, the sales and uses criterion is divided into six additional sub-criteria (Table 1). Amount used and areas treated by farmers in Wallonia are data worth considering for the evaluation of emissions at the regional scale. These data were obtained from the Direction de l'Analyse Économique Agricole of the Walloon Public Service for the year 2012. The number of crops on which the CUP can be applied is also considered. Indeed, different crops undergo different pressures at different periods, therefore conditioning the pesticides uses. Broadspectrum CUPs can be used on several different crops or against several different pests. Therefore, such CUPs can be used not only in larger amount but also during longer periods 
compared to more specific CUPs. Emissions of pesticides in atmosphere are higher from permanent crops, such as orchards, than emissions from non-permanent crops (e.g., cereal, maize, potato...) conditioning spatial and temporal concentrations in ambient air (Sarigiannis et al. 2013). The number of commercial products containing the CUP is also considered in the ranking method. Finally, non-professional uses and biocidal uses (both professional and non-professional), in commercial products, might also contribute to increase the amount of CUPs released in the atmosphere. Therefore, these data are also considered in the sales and uses criterion. The sales and uses data (i.e., professional and non-professional uses, type of crops treated, amount sold, and the number of commercial product containing the CUP) were obtained from the Federal Public Service of Health, Food Chain Safety and Environment website in autumn 2014 (http://fytoweb.be).

\section{Criterion 3: presence in ambient air}

The third criterion used in this ranking method is the potential presence in ambient air. This criterion is divided into four subcriteria (Table 1). The first is volatility and is assessed based on two relevant physicochemical properties of CUPs, namely vapor pressure and Henry's law constant. Henry's law constant measures the volatilization tendency of a pesticide from dilute solution, whereas vapor pressure is a measurement of volatilization of the pure compound in its condensed state. Volatility is defined as "low" for CUPs with a vapor pressure $<1.10^{-4} \mathrm{~Pa}$ and a Henry's law constant $<1.10^{-5} \mathrm{~Pa} \mathrm{~m}^{3} / \mathrm{mol}$, as "high" for CUPs with a vapor pressure $>1.10^{-4} \mathrm{~Pa}$ and a Henry's law constant $>1.10^{-5} \mathrm{~Pa} \mathrm{~m}^{3} / \mathrm{mol}$, and as "medium" for other CUPs (Bedos et al. 2002; Espallardo et al. 2012; Lichiheb et al. 2015). Data used for the three other subcriteria (i.e., maximum concentration measured in ambient air, number of studies that measured CUP concentrations in ambient air, and last year of detection) are compiled from scientific literature reporting CUPs' ambient air concentrations. In addition to peer-reviewed literature, reports from different French Accredited Associations for Air Quality Monitoring (AASQA) are also thoroughly investigated. Indeed, these regional associations monitor ambient air concentrations of several CUPs not only in rural but also in urban locations sometimes for more than a decade. France is a neighboring country with similar agricultural practices. Therefore, the last year of detection of CUPs in a French study is considered as particularly relevant information in the ranking method.

\section{Robustness of the ranking method}

To assess the robustness of the ranking method, points allocated to sub-criteria are modified to increase or reduce the weight of each criterion in the final score. Based on the points attributed as shown in Table 1, the most important criterion is sales and uses and accounts for a maximum of $44 \%$ of the total score, whereas presence in ambient air and chronic toxicity criteria are of similar weight (27 and $29 \%$, respectively). Two alternative ranking methods are used. In the second ranking method, chronic toxicity is the most important criterion with $41 \%$ of the total points, followed by sales and uses criterion that accounts for $36 \%$ and presence in ambient air criterion represents $22 \%$. Using the third ranking method, points attributed to presence in ambient air, sales and uses, and chronic toxicity accounted for 43,34 , and $23 \%$, respectively. The top 60 CUPs identified with each of the three ranking methods are further investigated for the possibility of analysis using a multi-residue analytical method. CUPs finally selected will be submitted to the analytical method development and validation.

\section{Results and discussion}

\section{Currently used pesticides selection}

In Belgium, 303 plant protection products were registered for both professional and non-professional uses in 2014. This high number of chemicals prevents the ease of use of a ranking method that attributes points to several criteria. Therefore, before ranking CUPs that will be monitored in ambient air, we first used a selection method that helped reducing the number of candidates from 303 to 108 (Fig. 1). The first reduction of the candidate list consisted in the removal of 72 plant protection (i.e., microorganisms, molecules derived from plants and animals, insect pheromones, and other plant protection products) that are out of the scope of the project. The number of candidate CUPs is further reduced using data on sales and uses as well as chronic toxicological information available in databases (Fig. 1).

\section{Selection based on sales and uses}

Between 2010 and 2013, cumulative amounts of 79 CUPs represented $95 \%$ of the total amount of CUPs sold to professional and non-professional users in Belgium that is $18,757 \mathrm{t}$ (supplementary material, Table S1). Two CUPs, the fungicide mancozeb and the herbicide glyphosate, contributed to almost $30 \%$ of this amount. Asulam is discarded from the candidate list as it was banned for use in Belgium by the end of 2012 .

\section{Selection based on chronic toxicity}

The databases consulted for toxicological data (i.e., carcinogenicity, neurotoxicity, endocrine disruption, developmental and reproductive toxicity, and mutagenicity and genotoxicity) allow identifying 53 CUPs potentially toxic for human health 


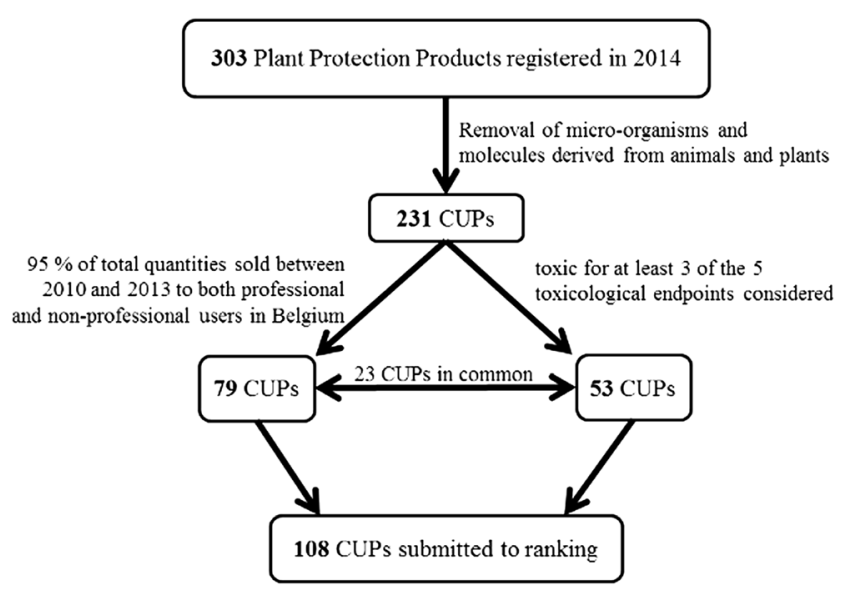

Fig. 1 Selection method used to reduce the number of CUPs considered for the final ranking method

for at least three toxicological endpoints (supplementary material, Table S2).

One hundred and ten CUPs are identified as possible, probable, or known carcinogens in at least one of the four databases consulted (Table 2). The data not only from human and experimental animal studies but also from mechanistic and other relevant data available are evaluated by working groups that define the strengths of evidence between exposure and carcinogenicity (IARC 2006; Cogliano et al. 2011). The classification of carcinogens based on the strengths of evidence highlighted that 54 CUPs are defined as "possibly carcinogenic to humans" in at least one of the four databases, whereas 28 CUPs are defined as "probably carcinogenic to humans" and 28 others are defined as "known carcinogens" (Table 2). Interestingly, 23 CUPs of the 95\% most sold in Belgium between 2010 and 2013 are listed as probable (12) or known carcinogens (11). Moreover, the cumulative amount sold for

Table 2 Number of CUPs classified for their toxicological endpoints in at least one of the database consulted (total of 231 CUPs considered)

\begin{tabular}{lc}
\hline Carcinogenicity & \\
Known & 28 \\
Probable & 28 \\
Possible & 54 \\
Not likely & 121 \\
Neurotoxicity & \\
$\quad$ Suspected or proved & 74 \\
Not likely & 157 \\
Endocrine disruption & \\
$\quad$ Suspected or proved & 49 \\
$\quad$ Not likely & 182 \\
Reproductive and developmental toxicity \\
$\quad$ Suspected or proved & 162 \\
Not likely & 69 \\
Mutagenicity and genotoxicity & \\
Suspected or proved & 15 \\
Not likely & 216 \\
\hline
\end{tabular}

these 23 CUPs represents almost half (i.e., 48.2\%) the total quantity sold during this period in Belgium (known carcinogens represent alone 14.3\%). This highlights that even though CUPs are suspected or recognized as human carcinogens, some were still sold in large quantities between 2010 and 2013. This is particularly emphasized by mancozeb, which is listed as probably carcinogenic to humans in at least one of the four databases consulted and was the most sold CUPs between 2010 and 2013 (supplementary material, Tables S1 and S2).

The strengths of evidence for other toxicological endpoints are weaker as data are less available for these endpoints and are therefore not considered (Sugeng et al. 2013). Thus, for the four other toxicological endpoints (i.e., neurotoxicity, endocrine disruption, developmental and reproductive toxicity, and mutagenicity and genotoxicity), CUPs are either classified as suspected/proved toxicants or as non-toxic. These criteria are assessed using the two databases dedicated to pesticides (i.e., PPDB and SAgE). Approximately one third of CUPs, (i.e., 74 CUPs) are identified for potential neurotoxic effects (Table 2) among which 32 contribute to the $95 \%$ most sold in Belgium between 2010 and 2013. Similarly to carcinogens, cumulative amount of CUPs with suspected or proved neurotoxicity also represents $48.2 \%$ of the total quantities sold in Belgium between 2010 and 2013. Epidemiological studies that investigated neurotoxicity of pesticides on human mainly focused on neurobehavioral and neurodevelopmental impacts of prenatal and perinatal exposure of children and on neurologic effects of adult occupationally exposed to pesticides (Koureas et al. 2012). These studies mainly focused on organophosphate, carbamate, and pyrethroid pesticides. Still, some carbamate pesticides in our list (e.g., metam sodium, metam potassium, prosulfocarb, and phenmedipham) and a pyrethroid (tau-fluvalinate) are not identified as neurotoxic. The cumulated amount sold of the other 28 organophosphate, carbamate, and pyrethroid pesticides identified as neurotic represents $27.2 \%$ of the total quantities sold in Belgium between 2010 and 2013. Sales of mancozeb, a carbamate fungicide, represent alone $16.9 \%$ of the Belgian sales during this period (supplementary material, Table S1).

Endocrine disruptors can affect human health through interactions with hormone synthesis, hormone storage and/or release, hormone transport or clearance, and hormone receptor binding or post-receptor activation (Damstra et al. 2002). These interactions with the endocrine system can lead to alterations of the reproduction (e.g., reduced semen quality, adverse pregnancy outcomes) and of the development (e.g., delayed puberty, development of secondary sex characteristics) in humans (Kortenkamp et al. 2011; Bergman et al. 2013). Only 49 out of the 231 CUPs are identified as potential endocrine disruptors. The cumulated amount of these potential endocrine-disrupting CUPs represents $35.6 \%$ of the total amount sold in Belgium between 2010 and 2013. Twenty 
CUPs of the $95 \%$ most sold in Belgium between 2010 and 2013 are identified as potential endocrine disruptors. Testing methods available for the assessment of endocrine properties mainly focus on in vitro interaction with receptors (Bergman et al. 2013). However, assessment of endocrine disruption is difficult as these effects present non-linear dose-response relationship. Moreover, endocrine-disrupting impacts on health depend on the period of exposure during the organisms' life cycle (Kortenkamp et al. 2011; Bergman et al. 2013). With the development of new tests and the increasing literature on endocrine-disrupting effects of pesticides in vitro as well as in vivo, the number of CUPs identified with endocrinedisrupting properties will probably increase. Several specific lists identifying endocrine-disrupting pesticides are developed by governments and intergovernmental organizations. Therefore, using these lists might help better identify potential endocrine-disrupting CUPs.

For developmental and reproductive toxicity, 162 CUPs are listed in at least one of the two databases consulted as suspected or proved toxicants. This appears to be a particularly high number. Indeed, in a hazard-ranking method used in Yuma County, Arizona, USA, only 7 out of the 74 pesticides considered were associated with reproductive and developmental toxicity (Sugeng et al. 2013). The high proportion of CUPs ranked for this toxicological endpoint in our study is influenced by the PPDB database in which 156 CUPs are classified as probable (97) or known (59) reproductive and/ or developmental toxicants. In contrast, SAgE database only identified 12 CUPs with possible reproductive effects on animals and 39 CUPS with possible (22) or confirmed (17) developmental effects on animals. This observation suggests that it might be useful to also consider peer-reviewed literature to improve the hazard assessment for CUPs (Sugeng et al. 2013). In our selection, we also consider mutagenicity and genotoxicity as additional health effect. To our knowledge, it is the first study that includes this toxicological endpoint for the classification of CUPs. However, data for these endpoints are scarce, and only 15 CUPs are identified for their genotoxicity and/or mutagenicity among which only glutaraldehyde is not identified for any of the other toxicological endpoints. Nevertheless, these 15 CUPs accounted for $24.8 \%$ of the total quantities sold in Belgium between 2010 and 2013.

In this study, only 30 CUPs are never identified for any of the five toxicological endpoints analyzed, and their cumulated amounts sold between 2010 and 2013 only represent $6.2 \%$ of the total quantities of CUPs sold during this period in Belgium. In contrast, 23 out of the 53 CUPs potentially toxic for at least three toxicological endpoints are among the 95\% most sold CUPs in Belgium between 2010 and 2013 (Fig. 1). These 23 CUPs accounted for $37.3 \%$ of the total quantities sold during this period. It should be noted that 6 CUPs are identified in at least one of the databases consulted as toxic for each of the five toxicological endpoints (supplementary material, Table S2). Quantities of these 6 CUPs sold between 2010 and 2013 in Belgium accounted for $21.4 \%$ of total sales (supplementary material, Table S1).

Sugeng et al. (2013) observed that approximately $80 \%$ of the total pesticide amount used in Yuma County, Arizona, USA, between 2006 and 2011 was associated with chronic toxicity (i.e., cancer, endocrine disruption, and/or reproductive/developmental toxicity). Therefore, monitoring concentrations of CUPs suspected or known for their toxicity in humans and sold in large quantities appears important to evaluate population exposure and the subsequent potential health effects. The use of quantities sold in Belgium between 2010 and 2013 and of data on the five toxicological endpoints helped to reduce the number of CUPs candidates for ambient air monitoring in Wallonia from 231 to 108 (Fig. 1). These CUPs are then further submitted to the ranking method using the sub-criteria of the three main criteria (i.e., chronic toxicity, sales and uses, and presence in ambient air) (Table 1).

\section{Currently used pesticide ranking}

Points are attributed for all the 17 sub-criteria to each of the 108 CUPs based on data available in pesticides databases, international studies and reports on ambient air monitoring, along with data from national and regional sales and uses as presented in the Table 1. Two additional methods are used for the attribution of points in order to assess robustness of the ranking and avoid potential bias due to overestimation of one criterion over the two others. The first method (Table 1) attributes more points to the sales and uses criterion, whereas in the second and third methods, the most important criteria are chronic toxicity and presence in ambient air, respectively. The 60 CUPs with the highest total score after ranking using each of the three methods are identified as candidates for analytical method development (supplementary material, Table S3). Sixty-six CUPs are identified in at least one top 60 of the three ranking methods. Interestingly, only 14 CUPs are not identified in the top 60 of all the ranking methods (supplementary material, Table S3). This highlights that even if adjustments are used to mitigate the importance of the three main criteria in the ranking, the most interesting CUPs to assess in ambient air could be consistently identified. The first method of points attribution (Table 1) is used to further discuss results.

All CUPs have a total score of 23 or higher on a maximum of 48 points attributed using the ranking method 1 (Table 3 ). The highest score is attributed to chlorothalonil with 38 points. Indeed, chlorothalonil was used in large quantities in Wallonia on wheat, beet, and potato crops and was measured in ambient air in several studies in Europe and North America (White et al. 2006; Yao et al. 2006; Gouin et al. 2008; Schummer et al. 2010; Coscollà et al. 2011; Garron et al. 2012). Among these studies, the highest chlorothalonil concentration 
Table 3 Total scores attributed to the 66 CUPs for the three main criteria using ranking method 1

\begin{tabular}{|c|c|c|c|c|c|c|}
\hline $\begin{array}{l}\text { Currently used } \\
\text { pesticides }\end{array}$ & CAS number & Chemical family & $\begin{array}{l}\text { Score for chronic } \\
\text { toxicity }\end{array}$ & $\begin{array}{l}\text { Score for sales } \\
\text { and uses }\end{array}$ & $\begin{array}{l}\text { Score for presence in } \\
\text { ambient air }\end{array}$ & $\begin{array}{l}\text { Total of } \\
\text { points }\end{array}$ \\
\hline Chlorothalonil & $1897-45-6$ & Chloronitrile & 7 & 19 & 12 & 38 \\
\hline Cymoxanil & $57966-95-7$ & Cyanoacetamide oxime & 9 & 16 & 12 & 37 \\
\hline Fluazinam & $79622-59-6$ & Phenylpyridinamine & 11 & 15 & 11 & 37 \\
\hline MCPA & $94-74-6$ & Aryloxyalkanoic acid & 10 & 20 & 7 & 37 \\
\hline $2,4-\mathrm{D}$ & $94-75-7$ & Aryloxyalkanoic acid & 10 & 16 & 10 & 36 \\
\hline Epoxiconazole & $133855-98-8$ & Triazole & 8 & 17 & 11 & 36 \\
\hline Mecoprop-P & $16484-77-8$ & Aryloxyalkanoic acid & 7 & 17 & 12 & 36 \\
\hline Pendimethalin & $40487-42-1$ & Dinitroaniline & 7 & 16 & 13 & 36 \\
\hline Tebuconazole & 107534-96-3 & Triazole & 8 & 18 & 10 & 36 \\
\hline Dimethenamid-P & $163515-14-8$ & Chloroacetamide & 7 & 17 & 11 & 35 \\
\hline Linuron & $330-55-2$ & Urea & 10 & 16 & 9 & 35 \\
\hline Prochloraz & $67747-09-5$ & Imidazole & 11 & 16 & 8 & 35 \\
\hline Propiconazole & $60207-90-1$ & Triazole & 10 & 16 & 9 & 35 \\
\hline Terbuthylazine & $5915-41-3$ & Triazine & 8 & 16 & 11 & 35 \\
\hline Cypermethrin & $52315-07-8$ & Pyrethroid & 10 & 14 & 10 & 34 \\
\hline Fenpropimorph & $67564-91-4$ & Morpholine & 6 & 15 & 13 & 34 \\
\hline Mancozeb & 2234562 & Carbamate & 12 & 19 & 3 & 34 \\
\hline Chlorpyrifos & $2921-88-2$ & Organophosphate & 10 & 10 & 13 & 33 \\
\hline Dimethoate & $60-51-5$ & Organophosphate & 14 & 10 & 9 & 33 \\
\hline Deltamethrin & $52918-63-5$ & Pyrethroid & 9 & 12 & 11 & 32 \\
\hline Diflufenican & $83164-33-4$ & Carboxamide & 3 & 18 & 11 & 32 \\
\hline Ethofumesate & $26225-79-6$ & Benzofuran & 4 & 17 & 11 & 32 \\
\hline Prosulfocarb & $52888-80-9$ & Thiocarbamate & 4 & 16 & 12 & 32 \\
\hline S-metolachlor & $87392-12-9$ & Chloroacetamide & 5 & 14 & 13 & 32 \\
\hline Triallate & $2303-17-5$ & Thiocarbamate & 9 & 11 & 12 & 32 \\
\hline Flufenacet & $142459-58-3$ & Oxyacetamide & 10 & 19 & 2 & 31 \\
\hline Aclonifen & $74070-46-5$ & Diphenyl ether & 6 & 13 & 11 & 30 \\
\hline Difenoconazole & $119446-68-3$ & Triazole & 7 & 16 & 7 & 30 \\
\hline Iprodione & $36734-19-7$ & Dicarboximide & 10 & 11 & 9 & 30 \\
\hline Isoproturon & $34123-59-6$ & Urea & 5 & 17 & 8 & 30 \\
\hline Oxadiazon & 19666-30-9 & Oxidiazole & 8 & 9 & 13 & 30 \\
\hline Boscalid & $188425-85-6$ & Carboxamide & 6 & 16 & 7 & 29 \\
\hline Dichlorprop-P & $15165-67-0$ & Aryloxyalkanoic acid & 8 & 12 & 9 & 29 \\
\hline Flusilazole & 85509-19-9 & Triazole & 10 & 8 & 11 & 29 \\
\hline Glyphosate & $1071-83-6$ & Phosphonoglycine & 1 & 20 & 8 & 29 \\
\hline Metaldehyde & $9002-91-9$ & Cyclo-octane & 11 & 15 & 3 & 29 \\
\hline Spiroxamine & 118134-30-8 & Morpholine & 3 & 13 & 13 & 29 \\
\hline Thiram & $137-26-8$ & Carbamate & 13 & 14 & 2 & 29 \\
\hline Alpha-cypermethrin & $67375-30-8$ & Pyrethroid & 9 & 10 & 9 & 28 \\
\hline Chlorpropham & $101-21-3$ & Carbamate & 8 & 13 & 7 & 28 \\
\hline Tetraconazole & $112281-77-3$ & Triazole & 10 & 8 & 10 & 28 \\
\hline Captan & $133-06-2$ & Phthalimide & 3 & 12 & 12 & 27 \\
\hline Dimethomorph & $110488-70-5$ & Morpholine & 4 & 12 & 11 & 27 \\
\hline Fenoxycarb & $72490-01-8$ & Carbamate & 10 & 6 & 11 & 27 \\
\hline Fenpropidin & 67306-00-7 & Unclassified & 5 & 10 & 12 & 27 \\
\hline Metribuzin & 21087-64-9 & Triazinone & 7 & 13 & 7 & 27 \\
\hline Phenmedipham & $13684-63-4$ & Carbamate & 4 & 17 & 6 & 27 \\
\hline Pirimicarb & $23103-98-2$ & Carbamate & 6 & 10 & 11 & 27 \\
\hline
\end{tabular}


Table 3 (continued)

\begin{tabular}{|c|c|c|c|c|c|c|}
\hline $\begin{array}{l}\text { Currently used } \\
\text { pesticides }\end{array}$ & CAS number & Chemical family & $\begin{array}{l}\text { Score for chronic } \\
\text { toxicity }\end{array}$ & $\begin{array}{l}\text { Score for sales } \\
\text { and uses }\end{array}$ & $\begin{array}{l}\text { Score for presence in } \\
\text { ambient air }\end{array}$ & $\begin{array}{l}\text { Total of } \\
\text { points }\end{array}$ \\
\hline Prothioconazole & $178928-70-6$ & Triazolinthione & 7 & 18 & 2 & 27 \\
\hline Trifloxystrobine & $141517-21-7$ & Strobilurin & 3 & 15 & 9 & 27 \\
\hline Azoxystrobin & $131860-33-8$ & Strobilurin & 3 & 15 & 8 & 26 \\
\hline Cyprodinil & $121552-61-2$ & Anilinopyrimidine & 4 & 9 & 13 & 26 \\
\hline Dicamba & 1918-00-9 & Benzoic acid & 7 & 12 & 7 & 26 \\
\hline Metazachlor & $67129-08-2$ & Chloroacetamide & 4 & 11 & 11 & 26 \\
\hline Clopyralid & $1702-17-6$ & Pyridine compound & 3 & 16 & 6 & 25 \\
\hline Metamitron & 41394-05-2 & Triazinone & 6 & 17 & 2 & 25 \\
\hline Pyrimethanil & $53112-28-0$ & Anilinopyrimidine & 7 & 7 & 11 & 25 \\
\hline Thiophanate-methyl & $23564-05-8$ & Benzimidazole & 12 & 11 & 2 & 25 \\
\hline Amitrole & $61-82-5$ & Triazole & 14 & 9 & 1 & 24 \\
\hline Beta-cyfluthrin & $68359-37-5$ & Pyrethroid & 10 & 7 & 7 & 24 \\
\hline Bromoxynil & $1689-84-5$ & Hydroxybenzonitrile & 9 & 6 & 9 & 24 \\
\hline Carbendazim & $10605-21-7$ & Benzimidazole & 11 & 8 & 5 & 24 \\
\hline Chlorotoluron & $15545-48-9$ & Urea & 6 & 12 & 6 & 24 \\
\hline Fluroxypyr & $69377-81-7$ & Pyridine compound & 5 & 18 & 1 & 24 \\
\hline 2,4-DB & $94-82-6$ & Aryloxyalkanoic acid & 9 & 10 & 4 & 23 \\
\hline Metiram & $9006-42-2$ & Carbamate & 12 & 9 & 2 & 23 \\
\hline
\end{tabular}

measured was $108 \mathrm{ng} / \mathrm{m}^{3}$ in Center Region, France (Coscollà et al. 2010). This broad-spectrum fungicide was also detected in urban sampling sites as well as in forested areas located far from any agricultural uses suggesting long-range transport (White et al. 2006; Yao et al. 2006; Gouin et al. 2008; Garron et al. 2012; Wofford et al. 2014). Potential carcinogenicity of chlorothalonil is listed in the four databases consulted. Moreover, PPDB database identified this fungicide as known to cause reproduction and development effects. Chlorothalonil also received the third highest score in a ranking method developed by the California Department of Pesticide Regulation to select CUPs further analyzed in ambient air in California (Segawa et al. 2014).

A total score of 37 is attributed to cymoxanil, fluazinam, and MCPA. These CUPs are classified as suspected or proved toxicants for at least three endpoints (supplementary material, Table S2) and were all used in large quantities on large areas in Wallonia between 2010 and 2013. The fungicide cymoxanil was monitored in France and Spain (Sauret et al. 2008; Coscollà et al. 2013) but was only detected at concentrations above its quantification limit in France at a maximum of $40 \mathrm{ng} / \mathrm{m}^{3}$ in Britany (AirBreizh 2007). The fungicide fluazinam was also measured in some French studies, however, at a maximum concentration of $2.2 \mathrm{ng} / \mathrm{m}^{3}$ (Coscollà et al. 2010). The herbicide MCPA was only measured in Canada at a maximum concentration of $5.83 \mathrm{ng} / \mathrm{m}^{3}$ in an agricultural region (Aulagnier et al. 2008; Yao et al. 2008). None of these CUPs were ranked in the Californian ranking method
(Segawa et al. 2014). However, it was not specified if these pesticides were among the top 100 used in California.

Mancozeb is the CUP with the highest cumulative amount sold in Belgium and with the highest quantity used in Wallonia between 2010 and 2013. Furthermore, this carbamate fungicide is also suspected or proved toxicant for all toxicological endpoints (supplementary material, Table S2). However, mancozeb has only the fifth highest score (i.e., 34 points) of the 108 CUPs classified (Table 3). Indeed, to our knowledge, mancozeb was only investigated once in ambient air monitoring studies with concentrations always under detection limit of the analytical method (Baker et al. 1996). This lack of data on mancozeb concentrations is probably due to its degradation to ethylene thiourea (ETU) in the environment (Kurttio et al. 1990). ETU analysis requires specific methods and was never investigated along with other CUPs in ambient air. Moreover, other ethylene bisdiothiocarbamate fungicides such as maneb or zineb also degrade to ETU (Lentza-Rizos 1990), which implies that ETU measured in the environment can hardly be linked to the emissions of a particular CUP.

Glyphosate is the most sold and used herbicide worldwide and is the second most sold CUP in Belgium between 2010 and 2013 after mancozeb (supplementary material, Table S1). Yet, its total score in our selection method is only the 10th highest (Table 3). Indeed, this broad-spectrum herbicide is not reported as suspected or known human toxicant for any of the five toxicological endpoints in the databases. However, it should be noted that since the consultation of the databases, IARC classified 
Table 4 CUPs selected for the development of sampling and analysis methods for ambient air monitoring in Wallonia, Belgium, during a year

\begin{tabular}{|c|c|c|c|c|c|}
\hline Currently used pesticides & Chemical family & CUP class & Currently used pesticides & Chemical family & CUP class \\
\hline $2,4-\mathrm{D}$ & Alkylchlorophenoxy & Herbicides & Fluazinam & Phenylpyridinamine & Fungicides \\
\hline 2,4-DB & Alkylchlorophenoxy & Herbicides & Iprodione & Dicarboximide & Fungicides \\
\hline Aclonifen & Diphenyl ether & Herbicides & Linuron & Urea & Herbicides \\
\hline Alpha-cypermethrin & Pyrethroid & Insecticides & MCPA & Aryloxyalkanoic acid & Herbicides \\
\hline Boscalid & Carboxamide & Fungicides & Mecoprop-P & Aryloxyalkanoic acid & Herbicides \\
\hline Captan & Phthalimide & Fungicides & Metazachlor & Chloroacetamide & Herbicides \\
\hline Chlorothalonil & Chloronitrile & Fungicides & Metribuzin & Triazinone & Herbicides \\
\hline Chlorpyrifos & Organophosphate & Insecticides & Oxadiazon & Oxidiazole & Herbicides \\
\hline Clopyralid & Pyridine compound & Herbicides & Pendimethalin & Dinitroaniline & Herbicides \\
\hline Cymoxanil & Cyanoacetamide oxime & Fungicides & Pirimicarb & Carbamate & Insecticides \\
\hline Cypermethrin & Pyrethroid & Insecticides & Propiconazole & Triazole & Fungicides \\
\hline Cyprodinil & Anilinopyrimidine & Fungicides & Prosulfocarb & Thiocarbamate & Herbicides \\
\hline Deltamethrin & Pyrethroid & Insecticides & Pyrimethanil & Anilinopyrimidine & Fungicides \\
\hline Difenoconazole & Triazole & Fungicides & S-metolachlor & Chloroacetamide & Herbicides \\
\hline Diflufenican & Carboxamide & Herbicides & Spiroxamine & Morpholine & Fungicides \\
\hline Dimethenamid-P & Chloroacetamide & Herbicides & Tebuconazole & Triazole & Fungicides \\
\hline Dimethoate & Organophosphate & Insecticides & Terbuthylazine & Triazine & Herbicides \\
\hline Epoxiconazole & Triazole & Fungicides & Tetraconazole & Triazole & Fungicides \\
\hline Ethofumesate & Benzofuran & Herbicides & Thiram & Carbamate & Fungicides \\
\hline Fenoxycarb & Carbamate & Insecticides & Triallate & Thiocarbamate & Herbicides \\
\hline Fenpropidin & Morpholine & Fungicides & Trifloxystrobine & Strobilurin & Fungicides \\
\hline Fenpropimorph & Morpholine & Fungicides & & & \\
\hline
\end{tabular}

glyphosate as probably carcinogenic to humans (group 2A) (IARC 2015). Though, this modification has only little effect on its ranking. This change in classification highlights the need to constantly review knowledge on health effects associated to pesticide exposure, especially for endocrine disruption and reproductive and developmental toxicity outcomes (Sugeng et al. 2013). Glyphosate can be measured in ambient air along with its degradation product aminomethylphosphonic acid (AMPA) (Feng-chih et al. 2011; Majewski et al. 2014). Glyphosate and AMPA were detected in over $60 \%$ of air samples taken in Mississippi, Iowa, and Indiana, USA, throughout the growing season in 2007 and 2008 with a maximum concentration of $9.1 \mathrm{ng} / \mathrm{m}^{3}$ (Feng-chih et al. 2011; Majewski et al. 2014). Yet, glyphosate and AMPA analysis in ambient air requires an analytical method that is specific to these molecules and might not be included in a multi-residues method (Feng-chih et al. 2011; Majewski et al. 2014).

These observations highlight the need to evaluate each of the 66 CUPs to assess the possibility to develop multi-residues method that includes the highest number of different CUPs. Review of analytical method allowed a final selection of 43 CUPs that will be submitted to the further development of the sampling and analysis methods for ambient air assessment in Wallonia, Belgium. These 43 CUPs are listed in Table 4.

\section{Conclusions and perspectives}

In this study, we used a selection method followed by a ranking method that helped identify a manageable number of CUPs for a yearlong study on ambient air concentrations in Wallonia, Belgium. The selection method reduced the number of plant protection products considered in the ranking method from 303 to 108 . The criteria used for this selection were the origins (i.e., microorganisms, molecules derived from plants and animals, and insect pheromones), data on sales and uses, and chronic toxicological information.

The ranking method used 3 main criteria divided in a total of 17 sub-criteria. This method took into account not only toxicological endpoints but also national and regional data on sales and uses along with other uses criteria such as the number of commercial products containing the CUP or the number of crops that might be treated with the pesticide. Moreover, as the aim is to assess ambient air concentrations in Wallonia, probability to detect CUPs in ambient air was investigated using international, national, and regional studies as well as physicochemical properties. All these criteria were used in the ranking method to provide the most accurate identification of CUPs that might be measured in ambient air and that might potentially impact human health. 
Using three different methods of points attribution to criteria highlighted the robustness of the ranking method to identify the most interesting CUPs to assess in ambient air in Wallonia. These selection and ranking methods helped reduce the number of CUPs that will be analyzed in ambient air in Wallonia during 1 year from over 300 to 43 . Results of the monitoring study will provide better insight on spatial and temporal variations and help identify most preoccupant CUPs for human health in Wallonia. In the frame of the European Union Directive 2009/128/EC, which establishes a framework to achieve sustainable use of pesticides by reducing the risks and impacts of pesticides use on human health and the environment (OJEU 2009), it will be interesting to set up a second survey in a few years. Comparison of results of the present study with a future study will allow assessing effectiveness of regulations taken by the Walloon government.

Acknowledgements This work is part of the EXPOPESTEN project financially supported by ISSeP Funds using Moerman mechanism (article $275 / 3, \S 3$, of the Belgian Income Tax Code 92). Authors wish to thank members of the steering committee of the EXPOPESTEN project for their advices during development of the selection and ranking methods. Authors also thank the Direction de l'Analyse Économique Agricole (DAEA) of the Direction Générale Opérationnelle Agriculture, Ressources Naturelles et Environnement (DGO3) of the Walloon Public Service (SPW), and the Comite Régional PHYTO of the ASBL CORDER for the providing of data

\section{Compliance with ethical standards}

Conflict of interest The authors declare that they have no conflict of interest.

\section{References}

AirBreizh (2007) Campagne de mesures de produits phytosanitaires à Mordelles (35) du 12 avril au 5 juillet 2006

Aulagnier F, Poissant L, Brunet D et al (2008) Pesticides measured in air and precipitation in the Yamaska Basin (Québec): occurrence and concentrations in 2004. Sci Total Environ 394:338-348. https://doi. org/10.1016/j.scitotenv.2008.01.042

Baker LW, Fitzell DL, Seiber JN et al (1996) Ambient air concentrations of pesticides in California. Environ Sci Technol 30:1365-1368. https://doi.org/10.1021/es9506081

Baraud L, Tessier D, Aaron J-J et al (2003) A multi-residue method for characterization and determination of atmospheric pesticides measured at two French urban and rural sampling sites. Anal Bioanal Chem 377:1148-1152

Bedos C, Cellier P, Calvet R et al (2002) Mass transfer of pesticides into the atmosphere by volatilization from soils and plants: overview. Agronomie 22:21-33

Bergman Á, Heindel JJ, Jobling S et al (2013) State of the science of endocrine disrupting chemicals 2012: an assessment of the state of the science of endocrine disruptors prepared by a group of experts for the United Nations Environment Programme and World Health Organization. World Health Organization, Geneva

Cogliano VJ, Baan R, Straif K et al (2011) Preventable exposures associated with human cancers. J Natl Cancer Inst 103:1827-1839
Coscollà C, Colin P, Yahyaoui A et al (2010) Occurrence of currently used pesticides in ambient air of Centre Region (France). Atmos Environ 44:3915-3925

Coscollà C, Castillo M, Pastor A, Yusà V (2011) Determination of 40 currently used pesticides in airborne particulate matter (PM 10) by microwave-assisted extraction and gas chromatography coupled to triple quadrupole mass spectrometry. Anal Chim Acta 693:72-81

Coscollà C, Hart E, Pastor A, Yusà V (2013) LC-MS characterization of contemporary pesticides in PM10 of Valencia Region, Spain. Atmos Environ 77:394-403. https://doi.org/10.1016/j.atmosenv.2013.05. 022

Damstra T, Barlow S, Bergman A, Kavlock R, Van Der Kraak G (2002) Global assessment of the state-of the-science of endocrine disruptors. World Health Organization, Geneva, pp 11-32

Egeghy PP, Vallero DA, Cohen Hubal EA (2011) Exposure-based prioritization of chemicals for risk assessment. Environ Sci Pol 14:950 964. https://doi.org/10.1016/j.envsci.2011.07.010

Espallardo TV, Muñoz A, Palau JL (2012) Pesticide residues in the atmosphere. Pestic Eval Environ Pollut:203-232

EU (2014) EU pesticides database - active substances - Regulation (EC) $\mathrm{N}^{\circ} 1107 / 2009.28: 2014$. https://ec.europa.eu/food/plant/pesticides/ eu-pesticides-database/public/? event=activesubstance. selection\&language $=\mathrm{EN}$

Feng-chih C, Simcik MF, Capel PD et al (2011) Occurrence and fate of the herbicide glyphosate and its degradate aminomethylphosphonic acid in the atmosphere. Environ Toxicol Chem 30:548-555. https:// doi.org/10.1002/etc.431

Garron C, Ernst B, Julien G et al (2012) Concentrations and environmental risk of chlorothalonil in air near potato fields in Prince Edward Island, Canada. Pest Manag Sci 68:92-100

Gouin T, Shoeib M, Harner T (2008) Atmospheric concentrations of current-use pesticides across south-central Ontario using monthlyresolved passive air samplers. Atmos Environ 42:8096-8104. https://doi.org/10.1016/j.atmosenv.2008.05.070

Gunier RB, Harnly ME, Reynolds P et al (2001) Agricultural pesticide use in California: pesticide prioritization, use densities, and population distributions for a childhood cancer study. Environ Health Perspect 109:1071

Hart E, Coscollà C, Pastor A, Yusà V (2012) GC-MS characterization of contemporary pesticides in PM10 of Valencia Region, Spain. Atmos Environ 62:118-129. https://doi.org/10.1016/j.atmosenv.2012.08. 006

IARC (2006) Preamble to the IARC Monographs. Lyon, Fr Available online http//monographs iarc fr/ENG/Preamble/index php. Accessed 9:2015

International Agency for Research on Cancer (2015) IARC Monographs Volume 112: evaluation of five organophosphate insecticides and herbicides. World Health Organization, Lyon

Juraske R, Antón A, Castells F, Huijbregts MAJ (2007) PestScreen: a screening approach for scoring and ranking pesticides by their environmental and toxicological concern. Environ Int 33:886-893. https://doi.org/10.1016/j.envint.2007.04.005

Kamel F, Hoppin JA (2004) Association of pesticide exposure with neurologic dysfunction and disease. Environ Health Perspect 112:950 958

Kortenkamp A, Martin O, Faust M, et al (2011) State of the art assessment of endocrine disrupters. Final Report 23

Koureas M, Tsakalof A, Tsatsakis A, Hadjichristodoulou C (2012) Systematic review of biomonitoring studies to determine the association between exposure to organophosphorus and pyrethroid insecticides and human health outcomes. Toxicol Lett 210:155-168. https://doi.org/10.1016/j.toxlet.2011.10.007

Kurt-Karakus PB, Teixeira C, Small J et al (2011) Current-use pesticides in inland lake waters, precipitation, and air from Ontario, Canada. Environ Toxicol Chem 30:1539-1548. https://doi.org/10.1002/etc. 545 
Kurttio P, Vartiainen T, Savolainen K (1990) Environmental and biological monitoring of exposure to ethylenebisdithiocarbamate fungicides and ethylenethiourea. Br J Ind Med 47:203

LeNoir JS, McConnell LL, Fellers GM et al (1999) Summertime transport of current-use pesticides from California's Central Valley to the Sierra Nevada Mountain Range, USA. Environ Toxicol Chem 18: 2715-2722. https://doi.org/10.1002/etc.5620181210

Lentza-Rizos C (1990) Ethylenethiourea (ETU) in relation to use of ethylenebisdithiocarbamate (EBDC) fungicides. In: Ware GW (ed) Reviews of environmental contamination and toxicology: continuation of residue reviews. Springer New York, New York, pp 1-37

Lewis KA, Tzilivakis J, Warner DJ, Green A (2016) An international database for pesticide risk assessments and management. Hum Ecol Risk Assess An Int J 22:1050-1064. https://doi.org/10.1080/ 10807039.2015.1133242

Lichiheb N, Bedos C, Personne E, Barriuso E (2015) Synthèse des connaissances sur le transfert des pesticides vers l'atmosphère par volatilisation depuis les plantes 2268-3798. https://doi.org/10.4267/ pollutionatmospherique

Mai C, Theobald N, Lammel G, Hühnerfuss H (2013) Spatial, seasonal and vertical distributions of currently-used pesticides in the marine boundary layer of the North Sea. Atmos Environ 75:92-102. https:// doi.org/10.1016/j.atmosenv.2013.04.027

Majewski MS, Coupe RH, Foreman WT, Capel PD (2014) Pesticides in Mississippi air and rain: a comparison between 1995 and 2007. Environ Toxicol Chem 33:1283-1293. https://doi.org/10.1002/etc. 2550

Mitchell J, Arnot JA, Jolliet O et al (2013) Comparison of modeling approaches to prioritize chemicals based on estimates of exposure and exposure potential. Sci Total Environ 458-460:555-567. https:// doi.org/10.1016/j.scitotenv.2013.04.051

Mnif W, Hassine AIH, Bouaziz A et al (2011) Effect of endocrine disruptor pesticides: a review. Int J Environ Res Public Health 8: 2265-2303. https://doi.org/10.3390/ijerph8062265

Mostafalou S, Abdollahi M (2013) Pesticides and human chronic diseases: evidences, mechanisms, and perspectives. Toxicol Appl Pharmacol 268:157-177. https://doi.org/10.1016/j.taap.2013.01. 025

World Health Organization (2014) 13th report on carcinogens. National Toxicology Program. Public Health Service, Research Triangle Park, USA

OJEU (2009) Directive 2009/128/EC of the European parliament and of the council of 21 October 2009 establishing a framework for community action to achieve the sustainable use of pesticides. L309/71 2009/128/E: 16

OJEU (2011) Commission Regulation (EU) No 656/2011 of 7 July 2011 implementing Regulation (EC) No 1185/2009 of the European Parliament and of the Council concerning statistics on pesticides, as regards definitions and list of active substances Text with EEA relevanc. L180/3 36

Regional Belgian Plan: PWRP I (2013-2017) - Programme wallon de réduction des pesticides 2013-2017. https://agriculture.wallonie.be/
documents/20182/37931/20130122_Enqu\%25C3\%25AAte+ Pesticides_A4+FR_Interieur_PRINT.pdf/2e9b2a16-c414-4a3c9170-45f69 a $46653 \mathrm{f}$

Reus J, Leendertse P, Bockstaller C et al (2002) Comparison and evaluation of eight pesticide environmental risk indicators developed in Europe and recommendations for future use. Agric Ecosyst Environ 90:177-187. https://doi.org/10.1016/S0167-8809(01)00197-9

Samuel O, Dion S, St-Laurent L (2012) Indicateur de risque de pesticides du Québec: IRPeQ: santé et environnement (2e édition). Ministère de l'Agriculture, des Pêcheries et de l'Alimentation du Québec

Sarigiannis DA, Kontoroupis P, Solomou ES et al (2013) Inventory of pesticide emissions into the air in Europe. Atmos Environ 75:6-14

Sauret N, Wortham H, Putaud J-P, Mirabel P (2008) Study of the effects of environmental parameters on the gas/particle partitioning of current-use pesticides in urban air. Atmos Environ 42:544-553. https://doi.org/10.1016/j.atmosenv.2007.09.012

Scheyer A, Morville S, Mirabel P, Millet M (2007) Variability of atmospheric pesticide concentrations between urban and rural areas during intensive pesticide application. Atmos Environ 41:3604-3618

Schummer C, Mothiron E, Appenzeller BR et al (2010) Gas/particle partitioning of currently used pesticides in the atmosphere of Strasbourg (France). Air Qual Atmos Health 3:171-181. https:// doi.org/10.1007/s11869-010-0065-8

Segawa R, Levine J, Neal R, Brattesani M (2014) Community air monitoring for pesticides. Part 1: selecting pesticides and a community. Environ Monit Assess 186:1327-1341. https://doi.org/10.1007/ s10661-013-3507-6

Sheldon LS (2010) Chapter 42 - exposure framework. In: Krieger R (ed) Hayes' handbook of pesticide toxicology, Third edn. Academic Press, New York, pp 971-976

Sugeng AJ, Beamer PI, Lutz EA, Rosales CB (2013) Hazard-ranking of agricultural pesticides for chronic health effects in Yuma County, Arizona. Sci Total Environ 463-464:35-41. https://doi.org/10. 1016/j.scitotenv.2013.05.051

Chemicals Evaluated for Carcinogenic Potential. Office of Pesticide Programs. U.S. Environmental Protection Agency. Annual Cancer Report 2014

White LM, Ernst WR, Julien G et al (2006) Ambient air concentrations of pesticides used in potato cultivation in Prince Edward Island, Canada. Pest Manag Sci 62:126-136

Wofford P, Segawa R, Schreider J et al (2014) Community air monitoring for pesticides. Part 3: using health-based screening levels to evaluate results collected for a year. Environ Monit Assess 186:1355-1370. https://doi.org/10.1007/s10661-013-3394-x

Yao Y, Tuduri L, Harner Tet al (2006) Spatial and temporal distribution of pesticide air concentrations in Canadian agricultural regions. Atmos Environ 40:4339-4351

Yao Y, Harner T, Blanchard P et al (2008) Pesticides in the atmosphere across Canadian agricultural regions. Environ Sci Technol 42:59315937. https://doi.org/10.1021/es800878r

Yusà V, Coscollà C, Mellouki W et al (2009) Sampling and analysis of pesticides in ambient air. J Chromatogr A 1216:2972-2983 